\title{
ESTUDO DE VIABILIDADE ECONÔMICO-FINANCEIRA DA RECICLAGEM DE CONSTITUINTES DE RESÍDUOS DE CONSTRUÇÃO E DEMOLIÇÃO
}

\author{
Study of the economic and financial viability of recycling of constituents of \\ construction and demolition residues
}

\author{
Victor Hugo Stormovski Cesar ${ }^{1}$, Francieli Helena Bernardi², Felippe Martins Damaceno ${ }^{3}$
}

Recebido em 22 de janeiro de 2019; aceito em 05 de agosto de 2019; disponível on-line em 12 de maio de 2020.

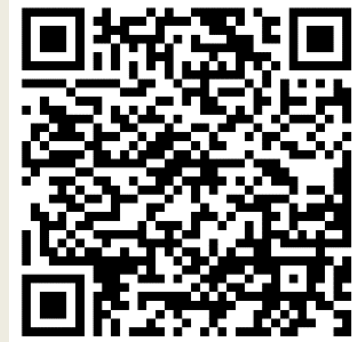

PALAVRAS CHAVE:

Rentabilidade;

Britadeira;

Sustentabilidade;

Construtora;

\section{KEYWORDS:}

Profitability;

Stone crusher;

Sustainability;

Construction company;

\section{* Contato com os autores:}

${ }^{1}$ e-mail: thestormovski@hotmail.com ( V. H. S. Cesar )

Engenheiro Civil pela Faculdade Assis Gurgacz (FAG).

2e-mail: bernardifrancieli@gmail.com ( F. H. Bernardi )

Doutora em Engenharia Agrícola pela Universidade Estadual do Oeste do Paraná (UNIOESTE).

${ }^{1}$ e-mail: felippemartins.utfpr@gmail.com ( F. M. Damaceno )

Doutorando em Engenharia Agrícola pela Universidade Estadual do Oeste do Paraná (UNIOESTE). 


\section{INTRODUÇÃO}

O setor da construção civil detém grande relevância econômica dentro do cenário brasileiro. Contudo, assim como qualquer atividade antrópica, tal setor causa impactos adversos ao meio ambiente. Parte significativa desses impactos está relacionada à grande demanda de recursos naturais e à geração de toneladas de resíduos de construção e demolição (RCD) (BARRA et al., 2006). De acordo com dados da Associação Brasileira das Empresas de Limpeza Pública e Resíduos Especiais (2017), cerca de 45,1 milhões de toneladas de RCD foram gerados e coletados no Brasil em 2016, desconsiderando-se os descartes clandestinos e irregulares que ocorreram.

Diante desse número expressivo, fica evidente e incontestável a importância da aplicação dos princípios de desenvolvimento sustentável no setor da construção civil, de modo a evitar desperdícios de materiais no decorrer de construções e grandes acúmulos de resíduos de obras em demolições e reformas. Outra medida que pode ser tomada, de modo a evitar ou minimizar os impactos gerados pelas construções e demolições, é a reciclagem e reutilização de RCD's nas próprias obras (SPADOTTO et al., 2011).

Dentre as vantagens de se utilizar os RCD's reciclados, destacam-se: preservação de recursos minerais não renováveis; suprimento da demanda de agregados em países desenvolvidos que convivem com o problema crônico de escassez de matérias primas; é uma alternativa para indústrias de equipamentos de mineração e britagem, uma vez que as pressões exercidas pelas legislações ambientais têm dificultado a exploração de recursos naturais; preservação e ampliação da vida útil dos aterros industriais; e possível redução dos custos associados às construções (LEVY, 1997).

Após a reciclagem, uma forma de aproveitamento de RCD como fragmento de concreto e restos cerâmicos, é utilizá-los na produção de contrapiso. O contrapiso é uma da camada responsável por receber o revestimento do piso, transmitir as cargas de utilização à laje suporte, proporcionar os desníveis entre os ambientes contíguos e embutir instalações hidráulicas e elétricas (BARROS; SABBATINI, 1991).

Tonus e Minozzi (2013) a partir de diversos testes de qualidade, relataram que o concreto produzido com RCD's reciclados (cerâmica vermelha britada), apresenta resistência superior ao concreto convencional e, portanto, poderia ser utilizado para finalidades mais nobres, ou até mesmo ser utilizado em contrapisos com grandes capacidades de carga e com um alto desempenho. Milhomem et al. (2018) tiveram conclusões similares adicionando isoladores elétricos de cerâmica ao concreto.

É inquestionável que a utilização dos RCD reciclados nas próprias obras ou para outros fins é ambientalmente vantajoso pela economia de recursos naturais, e trabalhos disponíveis na literatura atestam que a utilização desses materiais não afeta a qualidade do produto final, desde que feita de modo adequado. Entretanto, um mapping study mostrou que a literatura apresenta poucos estudos de viabilidade econômico-financeira contemplando a rentabilidade de projetos que versem a reciclagem de RCD's em obras.

\section{OBJETIVO}

O objetivo deste trabalho consistiu em avaliar a viabilidade econômico-financeira de empreendimentos de construção e demolição realizarem a reciclagem de fragmentos de concreto e cerâmica.

\section{RESÍDUOS DE CONSTRUÇÃO E DEMOLIÇÃO}

Resíduos de construção e demolição (RCD's) pode ser definido como todo e qualquer entulho proveniente do desperdício na construção, preparação e escavação de terrenos, reformas, reparos e demolição de estruturas como prédios, residências e pontes. Sua composição é muito variada e tem relação com a região e tipo de obra civil desenvolvida (Tabela 1). 


\begin{tabular}{lccccc}
\multicolumn{7}{c}{ TABELA 1: Fonte geradora e componentes dos RCD (em \%). } \\
Componentes & $\begin{array}{c}\text { Trabalhos } \\
\text { rodoviários }\end{array}$ & Escavações & $\begin{array}{c}\text { Sobras de } \\
\text { demolições }\end{array}$ & Obras diversas & $\begin{array}{c}\text { Sobras de } \\
\text { limpeza }\end{array}$ \\
\hline Concreto & 48,0 & 6,1 & 54,3 & 17,5 & 18,4 \\
Tijolo & 0,0 & 0,3 & 6,3 & 12,0 & 5,0 \\
Areia & 4,6 & 9,6 & 1,4 & 3,3 & 1,7 \\
Solo, poeira, lama & 16,8 & 48,9 & 11,9 & 16,1 & 30,5 \\
Rocha & 7,0 & 32,5 & 11,4 & 23,1 & 23,9 \\
Asfalto & 23,6 & 0,0 & 1,6 & 1,0 & 0,1 \\
Metais & 0,0 & 0,5 & 3,4 & 6,1 & 4,4 \\
Madeira & 0,1 & 1,1 & 1,6 & 2,7 & 3,5 \\
Papel/material orgânico & 0,0 & 1,0 & 1,6 & 2,7 & 3,5 \\
Outros & 0,0 & 0,0 & 0,9 & 0,9 & 2,0 \\
\hline
\end{tabular}

De modo geral, os RCD consistem em materiais compostos de cimento, cal, areia e brita (concretos, argamassa e blocos de concreto), materiais cerâmicos (telhas, manilhas, tijolos e azulejos) e materiais adjuntos como solo, gesso, metal, madeira, papel, plástico, graxa, material orgânico, vidro e isopor (CAMARGO, 1995; LEVY, 1997; PINTO, 1996; ZORDAN, 2000; BRASIL, 2002). Com fulcro no Artigo $3^{\circ}$ da Resolução CONAMA $n^{\circ}$ 307 de 2002, os RCD podem ser classificados da seguinte forma:

I. Classe A - são os resíduos reutilizáveis ou recicláveis como agregados, tais como: (a) de construção, demolição, reformas e reparos de pavimentação e de outras obras de infraestrutura, inclusive solos provenientes de terraplanagem; (b) de construção, demolição, reformas e reparos de edificações: componentes cerâmicos (tijolos, blocos, telhas, placas de revestimento etc.), argamassa e concreto; (c) de processo de fabricação e/ou demolição de peças pré-moldadas em concreto (blocos, tubos, meios-fios etc.) produzidas nos canteiros de obras;

II. Classe B - são os resíduos recicláveis para outras destinações, tais como: plásticos, papel/papelão, metais, vidros, madeiras e outros;

III. Classe C - são os resíduos que não foram desenvolvidas tecnologias ou aplicações economicamente viáveis que permitam a sua reciclagem/recuperação, tais como os produtos oriundos do gesso;

IV - Classe D: são resíduos perigosos oriundos do processo de construção, tais como tintas, solventes, óleos e outros ou aqueles contaminados ou prejudiciais à saúde oriundos de demolições, reformas e reparos de clínicas radiológicas, instalações industriais e outros, bem como telhas e demais objetos e materiais que contenham amianto ou outros produtos nocivos à saúde.

Cabe mencionar que grande parte da produção de resíduos da construção civil no Brasil é oriunda de desperdício de materiais em função de projetos incorretos, incompatibilização de projetos, falta de especificação e detalhamento em projetos e falhas de execução. Na Tabela 2 são apresentadas as taxas de desperdício no Brasil, contendo três categorias de taxas de desperdício devido à grande variação observada nos dados coletados. 
TABELA 2: Taxas de desperdício de materiais de construção no Brasil, em porcentagem.

\begin{tabular}{lccc} 
Materiais & Média & Mínima & Máxima \\
\hline Concreto usinado & 9 & 2 & 23 \\
Aço & 11 & 4 & 16 \\
Blocos e tijolos & 13 & 3 & 48 \\
Revestimento têxtil & 14 & 14 & 14 \\
Eletrodutos & 15 & 13 & 18 \\
Tubos & 15 & 13 & 18 \\
Tintas & 17 & 8 & 56 \\
Fios & 27 & 14 & 35 \\
Gesso & 30 & 14 & 20 \\
\hline
\end{tabular}

FONTE: ESPINELLI (2005).

De acordo com o Artigo 10 da Resolução CONAMA n ${ }^{\circ} 307$ de 2002, os resíduos da construção civil deverão ser destinados das seguintes formas: os da classe A deverão ser reutilizados ou reciclados na forma de agregados, ou encaminhados a áreas de aterro de resíduos da construção civil, sendo dispostos de modo a permitir a sua utilização ou reciclagem futura; os da classe $B$ deverão ser reutilizados, reciclados ou encaminhados a áreas de armazenamento temporário, sendo dispostos de modo a permitir a sua utilização ou reciclagem futura; os da classe $C$ deverão ser armazenados, transportados e destinados em conformidade com as normas técnicas específicas; e por fim, os da classe D deverão ser armazenados, transportados, reutilizados e destinados em conformidade com as normas técnicas específicas.

\subsection{GERAÇÃO, IMPACTOS AMBIENTAIS E RECICLAGEM DOS RCD}

Os RCD's representam um grave problema em muitas cidades brasileiras, sobretudo, pela sua significativa geração. Sabe-se que essa categoria de resíduos representam um problema que sobrecarrega os sistemas de limpeza pública municipais, visto que, no Brasil, os RCD's podem representar de $50 \%$ a $70 \%$ da massa dos resíduos sólidos urbanos (BRASIL, 2005).

Em 2016 o Brasil gerou aproximadamente 78,3 milhões de toneladas de resíduos sólidos urbanos. Considerando que aproximadamente $60 \%$ desse montante equivalem aos RCD's, estima-se que no mesmo ano, o país tenha gerado 46,98 milhões de toneladas de RCD's. Segundo dados referentes às coletas de RCD dos municípios brasileiros em 2016, foram coletadas cerca de 45,1 milhões de toneladas de RCD (ABRELPE, 2017). Possivelmente a diferença entre a estimativa de geração total de RCD e sua quantidade coletada, corresponde a descartes irregulares e clandestinos. Na Figura 1 está apresentada a quantidade de RCD coletada diariamente nas grandes regiões do Brasil nos anos de 2015 e 2016.

No Brasil, o descarte dos RCD's realizado de modo irregular tem acarretado uma série de impactos negativos à economia local dentro da malha urbana das cidades e ambientais na natureza. Isso porque esses resíduos têm causado ou facilitado enchentes, perda de infraestrutura de drenagem por obstrução das galerias pluviais e assoreamento de canais, proliferação de vetores transmissores de doenças graves, poluição e aumento dos custos da administração pública (ABRECON, 2015).

Em algumas cidades os RCD's são encaminhados à aterros sanitários, ação esta que é considerada como desperdício de dinheiro e espaço do aterro, isto porque esses materiais são passiveis de serem reciclados, proporcionando desta forma, redução dos impactos negativos associados aos RCD's (TONUS; MINOZZI, 2013). 


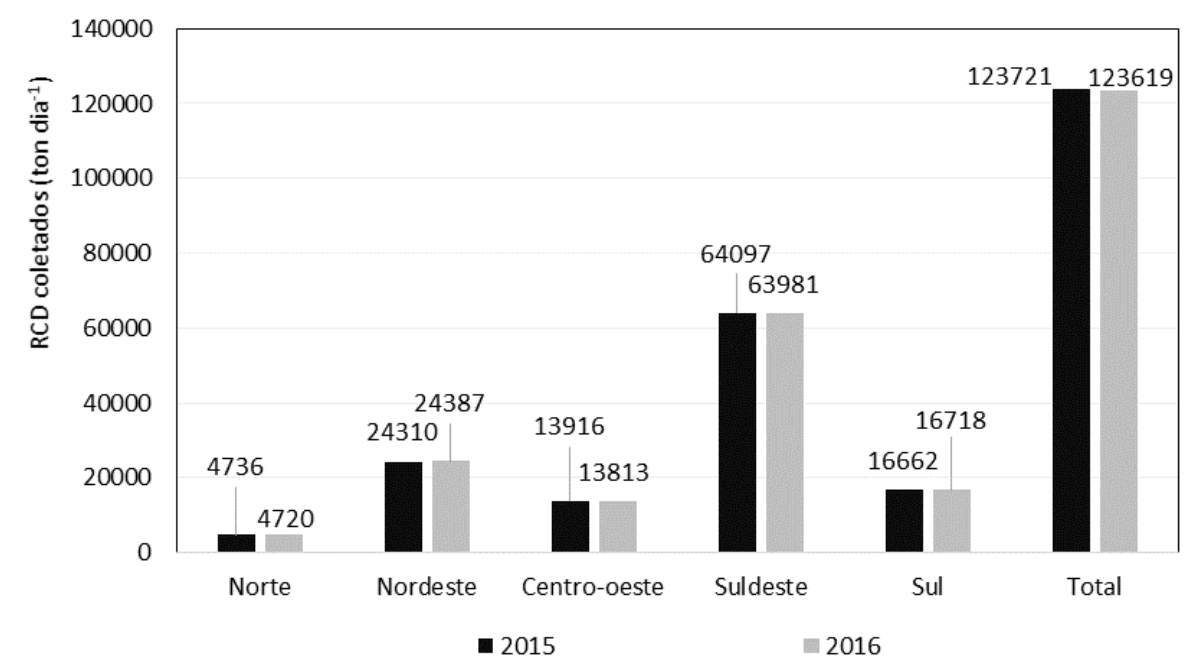

FIGURA 1: Quantidade de RCD coletada diariamente nas grandes regiões do Brasil nos anos de 2015 e 2016. FONTE: Adaptado de ABRELPE (2017).

Após a promulgação da resolução $\mathrm{n}^{\circ} 307$ do CONAMA em 2002 e da Lei Federal n 12.305 de 2010, que institui a Política Nacional de Resíduos Sólidos, houveram avanços expressivos no setor de reciclagem de RCD's no Brasil. Atualmente estimase que existam 310 usinas (considerando usinas fixas e móveis) de reciclagem desses materiais espalhadas pelo país (ABRECON, 2015).

Esses avanços são benéficos nos âmbitos econômico e ambiental, e refletem desenvolvimento sustentável, uma vez que com a reciclagem dos RCD's, os recursos minerais não renováveis são preservados, o suprimento da demanda de agregados em países desenvolvidos que convivem com o problema crônico de escassez de matérias primas é facilitado, as indústrias de equipamentos de mineração e britagem teriam mais uma alternativa de negócio (principalmente diante das atuais pressões exercidas pelas legislações ambientais que têm dificultado a exploração de recursos naturais), a vida útil dos aterros industriais seria prolongada, e haveriam possíveis reduções de custos associados às construções (LEVY, 1997).

A heterogeneidade é o principal gargalo na captação e reciclagem de resíduos provenientes de demolições, pois tal característica dificulta a coleta. Contudo, técnicas de desmantelamento seletivo estão sendo desenvolvidas para homogeneizar o material, facilitando desta forma, a reciclagem desses materiais. Para a utilização do entulho como agregado, primeiramente é feita uma seleção do entulho para a retirada dos materiais deletérios e, então, o entulho deve ser britado ou moído, dependendo da finalidade do seu uso (MIRANDA, 2008).

Como apresentado na Tabela 1, concreto e materiais cerâmicos correspondem a grandes proporções dos RCD's gerados em diversas obras civis. A reciclagem desses materiais é possibilitada por meio da britagem, isto é, trituração até uma determinada granulometria desejada, pois esse novo produto pode ser utilizado como agregado (pedra brita ou areia) na confecção de contrapisos (TONUS; MINOZZI, 2013).

Esses mesmos autores relatam que o concreto produzido com $\mathrm{RCD}$ 's reciclados (cerâmica vermelha britada), apresenta resistência superior ao concreto convencional e, portanto, poderia ser utilizado para finalidades mais nobres, ou até mesmo ser utilizado em contrapisos com grandes capacidades de carga e com um alto desempenho.

Na Figura 2 é possível visualizar a brita 0 obtida a partir da reciclagem resíduos de concreto e cerâmicas provenientes de construções e demolições. 


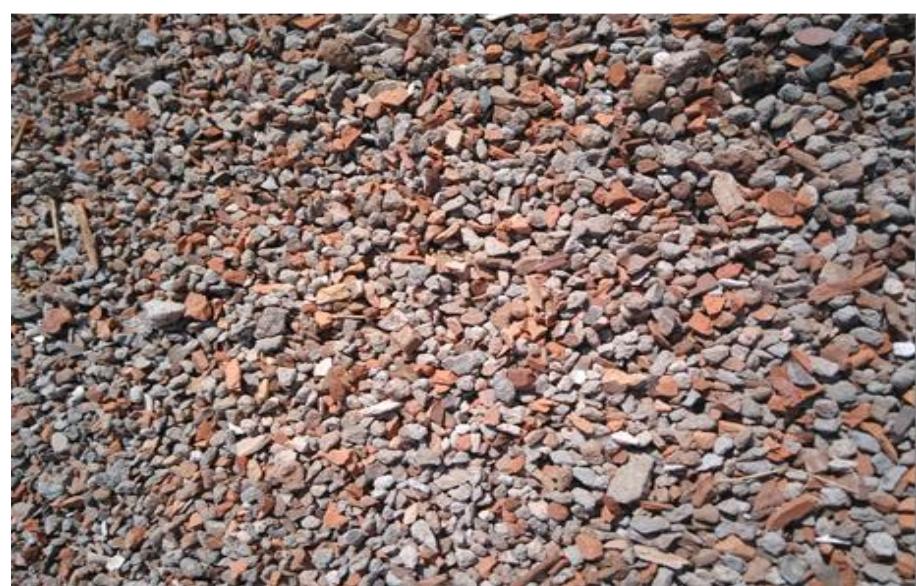

FIGURA 2: Pedra brita 0 reciclado em estoque.

FONTE: Future Reciclagem Inteligente, Cascavel-PR (acervo do autor).

\subsection{CONTRAPISO}

O contrapiso é uma das camadas do subsistema piso e apresenta diversas funções, dentre elas, destacam-se: possibilitar o recebimento do revestimento do piso, transmitir as cargas de utilização à laje suporte, proporcionar os desníveis entre os ambientes contíguos e permitir o eventual embutimento de instalações (BARROS; SABBATINI, 1991).

Os contrapisos podem ser classificados de acordo com sua aderência ao substrato em aderido, não aderido e flutuante. Além disso, podem ser classificados por número de camadas, tendo-se, por exemplo, contrapisos de camada única e de múltiplas camadas. No Quadro 1 são apresentados os tipos de contrapisos com suas respectivas especificações.

Para cumprir suas funções, o contrapiso deve apresentar diversas características e propriedades físicas. Segundo Barros e Sabbatini (1991), dentre essas características e propriedades, destacam-se a resistência mecânica, que pode ser dividida em resistência ao desgaste superficial por abrasão, resistência ao choque e ao puncionamento e resistência à tração; resistência de aderência e capacidade de absorver deformações; condições superficiais como nivelamento e regularidade superficial, rugosidade, porosidade e limpeza superficiais compatíveis com os revestimentos que serão aplicados.

\begin{tabular}{|c|l|}
\hline \multicolumn{2}{|c|}{ QUADRO 1: Tipos de contrapisos. } \\
\hline Tipos de Contrapisos & \multicolumn{1}{c|}{ Especificações } \\
\hline Contrapiso aderido & $\begin{array}{l}\text { Apresenta total aderência com a base. Suas espessuras } \\
\text { podem variar de } 20 \mathrm{~mm} \text { a } 40 \mathrm{~mm} \text {, pois trabalha de modo } \\
\text { conjunto com a laje. }\end{array}$ \\
\hline Contrapiso não aderido & $\begin{array}{l}\text { A aderência com a base não é essencial no desempenho } \\
\text { desse tipo de contrapiso, pois não é necessário o preparo e } \\
\text { limpeza da base. Quando não há aderência, a espessura da } \\
\text { camada desse tipo de contrapiso deve ser superior a } 35 \mathrm{~mm} .\end{array}$ \\
\hline Contrapiso flutuante & $\begin{array}{l}\text { É caracterizado pela presença de camadas intermediárias } \\
\text { de isolamento entr a camada de contrapiso e a base. Impete } \\
\text { totalmente a sua aderência. Nesse tipo de contrapiso, a } \\
\text { espessura da camada varia de } 40 \mathrm{~mm} \text { a } 70 \mathrm{~mm} .\end{array}$ \\
\hline
\end{tabular}

FONTE: Adaptado de Barros e Sabbatini (1991). 


\subsection{ADIÇÃOS DE AGREGADOS RECICLADOS DE BLOCOS CERÂMICOS EM CONCRETOS PARA CONTRAPISO}

Segundo Vieira e Dal Molin (2004), a utilização de proporções devidamente controladas de agregados reciclados no concreto, não afeta a durabilidade e muito menos a resistência do concreto em relação a corrosão das armaduras. Inclusive podem-se observar melhoras em algumas propriedades a partir destas adições. É possível afirmar também que há fortes indícios de economia de recursos em obras, quando se utiliza agregado reciclado.

Outra consequência da adição dos agregados reciclados em concretos diz respeito à distribuição e tipos de poros, os quais irão influenciar diretamente na resistência mecânica do concreto. Os agregados graúdos de RCD's reciclados são mais porosos que os agregados naturais. A porosidade dos agregados de RCD's também influenciará na massa específica aparente do concreto, logo, recomenda-se que essa massa seja determinada pela absorção de água. Angulo (2005) relata que a pasta de cimento endurecida e a presença da cerâmica vermelha nos RCD's, são os grupos de resíduos mais porosos presentes nesses agregados.

Entretanto, Tonus e Minozzi (2013) relatam que em função do material cerâmico apresentar maior porosidade, a absorção de água é um pouco maior, fazendo-se necessária a adição de um volume maior água para uma melhor trabalhabilidade do concreto. Para evitar patologias de fissuração, nesses casos, deve-se cuidar para que não se exagere na adição de água e de cimento, e que o contrapiso seja bem compactado.

\section{METODOLOGIA}

A metodologia utilizada para o desenvolvimento desta pesquisa possui caráter exploratório-aplicada, isto é, a partir de bases teóricas foram realizadas análises de interesse e passíveis de serem aplicados e para solução de problemas que ocorrem na realidade (MARCONI; LAKATOS, 1996).

Com o intuito de examinar a viabilidade econômico-financeira da reciclagem de RCD, a presente pesquisa foi organizada em três etapas sequenciais, conforme pode ser verificado na Figura 3.

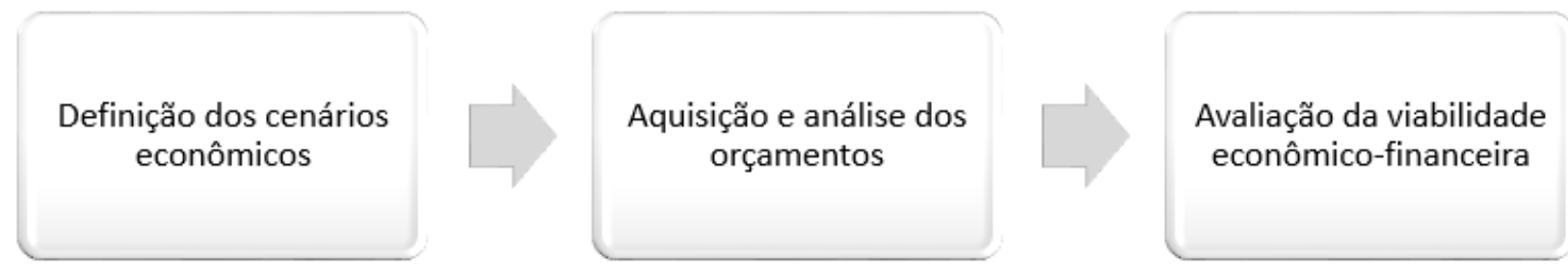

FIGURA 3: Etapas sequenciais do desenvolvimento da pesquisa. 


\subsection{DEFINIÇÃO DOS CENÁRIOS, ORÇAMENTOS E ANÁLISE DE VIABILIDADE ECONÔMICO- FINANCEIRA}

Inicialmente foram projetados quatro cenários econômicos, nos quais foram consideradas quatro construtoras (fictícias) especializadas em edificações, demolições e pequenas obras diversas de diferentes portes. Nos cenários um, dois, três e quatro foi levado em consideração que as construtoras produzem em média $1.000,800,600$ e 500 toneladas de RCD's por mês, respectivamente.

Sabe-se que em obras relacionadas a edificações, demolições e pequenas obras diversas, em média, 35,9\% dos RCD's equivalem a concreto e 9,15\% equivalem aos materiais cerâmicos (IPEA, 2012). Portanto, com base nessas porcentagens foram determinadas as quantidades desses materiais na geração de RCD das construtoras projetadas, vislumbrando suas reciclagens em pedras britas $n^{\circ} 0$, por meio de uma britadeira móvel tipo mandíbula (modelo BMD RA 700/6). A referida britadeira foi orçada diretamente com o fabricante em $\mathrm{R} \$ 830.000,00$ (no mês de janeiro de 2018), configurando, portanto, o custo de investimento inicial nos cenários. Os custos de operação (um funcionário capacidade e combustível) e manutenção (lubrificações e revisões) da britadeira foram considerados nas análises econômicas.

Como receitas, foram consideradas as valorações: a) da brita reciclada $n^{\circ} 0$, que poderia perfeitamente ser utilizada para a produção de contrapisos pela própria construtora ou ser vendida. A mesma foi orçada com base em três pontos comerciais de Cascavel-PR em $\mathrm{R} \$ 0,0206$ por kg; e b) da economia que as construtoras teriam com não contratação de caçambas de entulho (relativo ao concreto e cerâmica reciclados). Para realizar os cálculos das caçambas, foi considerado que a caçamba com capacidade de 8 toneladas custa $\mathrm{R} \$ 200,00$.
Para a análise de viabilidade econômicofinanceira da reciclagem de RCD's, todos os custos relacionados à aquisição, operação e manutenção da britadeira móvel, foram confrontados em fluxos de caixa, com as receitas provenientes do uso ou venda do material reciclado (concreto e cerâmica) na forma de brita $\mathrm{n}^{\circ} \mathrm{0}$, bem como da economia com caçambas de entulhos.

Os cenários econômicos foram projetados para um período de 15 anos, pois de acordo com o fabricante, é o tempo mínimo de vida útil da britadeira. A taxa mínima de atratividade (TMA) foi fixada em $7,9 \%$ com base em taxas de rendimento em poupança.

Com base nos fluxos de caixa dos cenários, foi determinado o fator de recuperação do capital (Payback descontado). A rentabilidade do projeto foi determinada por meio do valor presente líquido (VPL) (Equação (1)) e da taxa interna de retorno (TIR) (Equação (2)), ambas descritas por Casarotto e Kopittke (2008).

$$
\begin{gathered}
V P L=\sum_{n=0}^{t} \frac{F C_{n}}{(1+i)^{n}} \\
T I R=\sum_{n=0}^{t} \frac{F C_{n}}{(1+T I R)^{n}}
\end{gathered}
$$

Em que:

$F C=$ fluxo de caixa por período;

$i=$ taxa mínima de atratividade;

$t=$ tempo total do projeto (anos);

$n=$ período (anos).

\subsection{PRINCIPAIS CARACTERÍSTICAS DA BRITADEIRA RECICLADORA DE RCD}

De acordo com o fornecedor, a britadeira móvel tipo mandíbula é constituída de material $\operatorname{Hardox}^{\circledR}$, pesa 14,3 toneladas, possui boa distribuição de massa e é ideal para reciclagem de entulhos das mais diversas tenacidades. Possui motor à diesel (John Deere ${ }^{\circledR}$ ), com potência de 
98 kW e baixos níveis de emissão de gases, poeira e ruídos, o que possibilita sua utilização no meio urbano.

Os desenhos esquemáticos com as dimensões da britadeira são apresentados na Figura 4. A abertura superior para a entrada dos resíduos tem as medidas de $700 \times 500 \mathrm{~mm}$ com altura $2,9 \mathrm{~m}$ do solo. $\mathrm{O}$ volume total interno para o processamento de RCD's é de $4,3 \mathrm{~m}^{3}$, com capacidade de processar até 80 toneladas de material por hora. A abertura das mandíbulas é reajustável entre 30 e $80 \mathrm{~mm}$ e protegida contra ferrugem. Após a britagem de entulhos, os metais ferrosos são retirados da mistura por meio de separador magnético embutido.

A britadeira móvel processa resíduos com dimensões de até $65 \times 45 \mathrm{~cm}$. A capacidade de processamento varia em função do tamanho da fração desejável. Para frações de 0 até $45 \mathrm{~mm}$ a capacidade de processamento é até 40 toneladas por hora, e de 0 a $80 \mathrm{~mm}$, pode processar até 70 toneladas por hora. Seu índice de perdas é de até $1 \%$.

\section{RESULTADOS E DISCUSSÃO}

\subsection{RECEITAS}

Na Tabela 3 são apresentadas as receitas dos quatro cenários econômicos projetados, as quais resultaram dos benefícios associados à reciclagem de resíduos de concreto e cerâmicas dos RCD's para a produção de contrapisos.

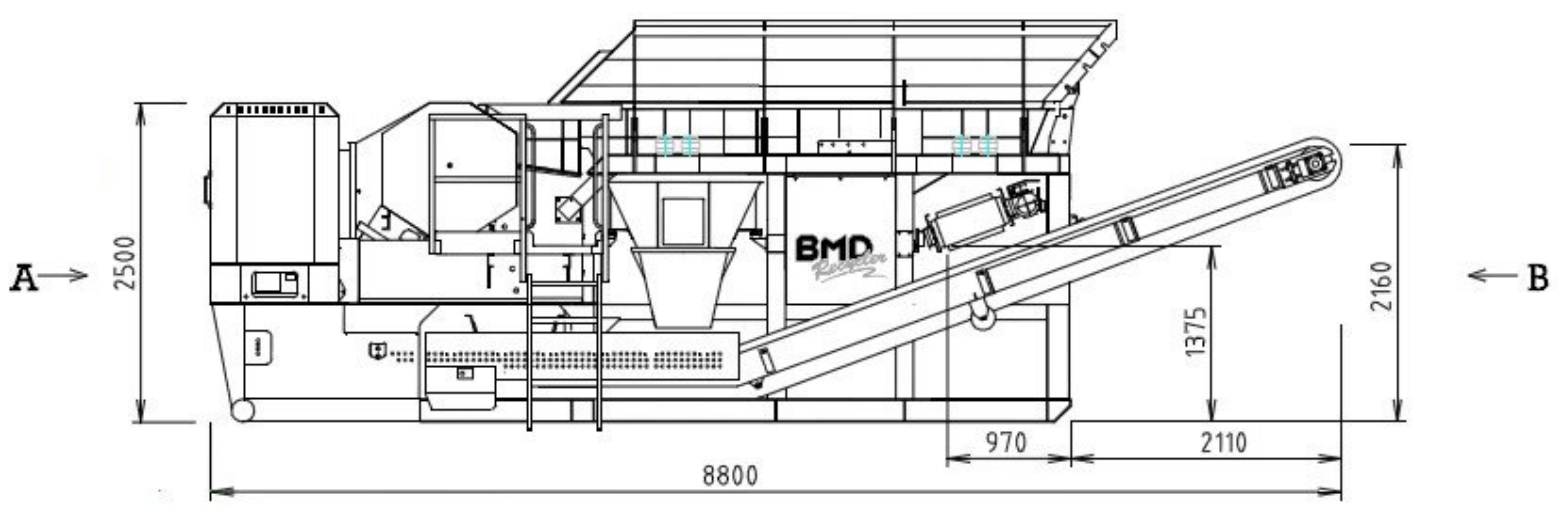

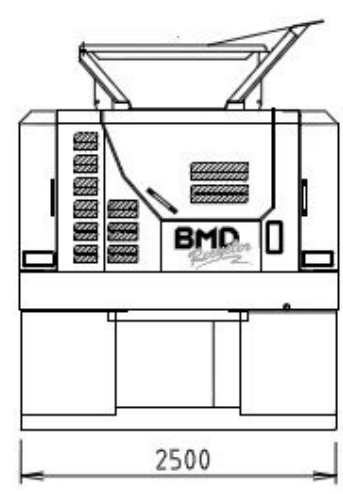

Vista da lateral A

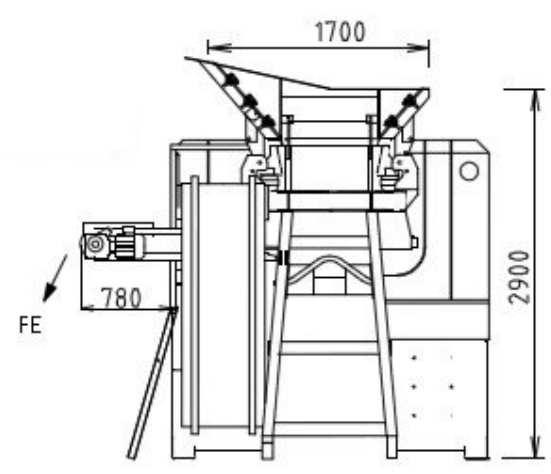

Vista da lateral B

FIGURA 4: Desenhos esquemáticos com as dimensões da britadeira móvel de mandíbula. FONTE: Fornecedor. 
TABELA 3: Receitas dos cenários econômicos projetados.

\begin{tabular}{|c|c|c|c|c|}
\hline Cenários & 1 & 2 & 3 & 4 \\
\hline Geração de RCD’s (toneladas ano ${ }^{-1}$ ) & $12.000,0$ & $9.600,0$ & $7.200,0$ & $6.000,0$ \\
\hline Geração de resíduo de concreto (toneladas ano ${ }^{-1}$ ) & $4.308,0$ & $3.542,4$ & $2.584,8$ & $2.154,0$ \\
\hline Geração de resíduo de cerâmica (toneladas ano-1) & $1.098,0$ & 974,4 & 658,8 & 549,0 \\
\hline Quantidade de caçambas que seriam necessárias & 675,8 & 564,6 & 405,5 & 337,9 \\
\hline Produção de reciclados de RCD's (toneladas ano ${ }^{-1}$ ) & $5.406,0$ & $4.516,8$ & $3.243,6$ & $2.703,0$ \\
\hline Receita referente a economia com caçambas ( $\left.R \$ a^{-1} o^{-1}\right)$ & $135.150,0$ & $112.920,0$ & $81.090,0$ & $67.575,0$ \\
\hline $\begin{array}{l}\text { Receita da utilização ou venda da brita } n^{\circ} 0 \text { reciclada ( } R \$ \\
a n o^{-1} \text { ) }\end{array}$ & $111.363,6$ & $93.046,1$ & $66.818,2$ & $55.681,8$ \\
\hline Receita total (R\$ ano $\left.{ }^{-1}\right)$ & $246.513,6$ & $205.966,1$ & $147.908,2$ & $123.256,8$ \\
\hline
\end{tabular}

Com a reciclagem somente dos resíduos de concreto e cerâmicas dos RCD nos cenários, seriam reduzidos $45,05 \%$ de todo o montante de resíduo encaminhados aos aterros especiais, ampliando desta forma, sua vida útil. Além disso, a reciclagem desses materiais em brita verificada nos cenários 1, 2, 3 e 4, preservaria a extração de aproximadamente 5.406, 4.516, 3.243, 2.703 toneladas por ano de recursos minerais da natureza, respectivamente. Vale ressaltar ainda que, com a menor necessidade de caçambas, além da economia proporcionada às construtoras, impactos como ruídos, poeiras e emissões de poluentes atmosféricos emitidos pelo escapamento dos caminhões que transportam as caçambas seriam evitados.

As receitas correspondentes à economia com caçambas de entulhos, foram ligeiramente maiores que as receitas atribuídas à venda ou utilização da brita $\mathrm{n}^{\circ} 0$ reciclada, correspondendo a $58,8 \%$ das receitas anuais totais nos cenários.

De modo geral, verificou-se que quanto maior é o porte da empresa, a tendência é que mais resíduos ela produza em função do maior número de obras e serviços, portanto, maior será também a possibilidade de reciclar RCD. Obviamente, tal aspecto resulta em maior quantidade de brita $\mathrm{n}^{\circ} 0$ reciclada e menor é a necessidade de caçambas de entulho, logo, as receitas são mais expressivas.

\subsection{CUSTOS}

$\mathrm{Na}$ Tabela 4 são apresentados os custos decorrentes da aquisição da britadeira móvel, bem como os custos anuais relacionados a sua operação e manutenções. Além do valor inicial demandado para a compra da britadeira ( $\mathrm{R} \$ 850.000,00)$, custos fixos anuais com manutenções periódicas de operação e prevenção foram considerados sob indicações do fornecedor, a saber, lubrificação, substituição da esteiras e correias, limpeza e manutenção nos trituradores. Os custos relacionados ao transporte da britadeira, que é móvel e por isso permite seu deslocamento até as obras, facilitando a logística dos RCD, foram considerados $\mathrm{R} \$ 4$ mil reais por ano em função do preço do combustível.

Além dos custos fixos supracitados, foi considerado também a contratação de um funcionário responsável pela operação da britadeira. Para tal, foi cotado um salário mensal de $\mathrm{R} \$ 1.846$, incluindo o $13^{\circ}$ salário. Também foi cotado o custo com equipamentos de proteção individual para os funcionários da obra (contendo abafador de ruídos, óculos, mascaras específicas com filtro, uniformes, luvas específicas e botinas de obra). 


\begin{tabular}{lc}
\multicolumn{2}{c}{ TABELA 4: Custos dos cenários projetados. } \\
\hline \multicolumn{2}{c}{ Custo inicial de investimento } \\
\hline Britadeira móvel tipo mandíbula (modelo BMD RA 700/6) & $\mathrm{R} \$ \mathbf{8 5 0 . 0 0 0 , 0 0}$ \\
\hline \multicolumn{1}{c}{ Custos Fixos } & $\mathrm{R} \$ 20.000,00$ \\
\hline Manutenções periódicas de operação e prevenção (anual) & $\mathrm{R} \$ 4.000,00$ \\
Transporte da britadeira (anual) & $\mathrm{R} \$ 24.000,00$ \\
Operador da máquina (anual) & $\mathrm{R} \$ 5.000,00$ \\
EPI's (anual) & $\mathrm{R} \$ \mathbf{5 3 . 0 0 0 , 0 0}$ \\
Total (anual)
\end{tabular}

\subsection{ANÁLISES ECONÔMICO-FINANCEIRAS}

Antes de tomar uma decisão de investimento, é mais que justificável recorrer a estudos de viabilidade econômico-financeira lastrados em bases seguras, para reduzir a probabilidade de resultados insatisfatórios e não incorrer a erros irreparáveis que se traduzem em prejuízos com o passar do tempo (CASAROTTO; KOPITTKE, 2008; JUNGES et al., 2009).

A variação do valor monetário ao longo do tempo é um fato. Considerar tal fator é fundamental em estudos de cunho econômico- financeiro, afinal o dinheiro tende a perder valor com o passar do tempo devido à inflação. Por isso se utiliza os métodos determinísticos de investimentos, pois esses levam em conta a variável tempo nos cálculos (CASAROTTO; KOPITTKE, 2008).

Na Figura 5 são apresentados os períodos de recuperação do capital investido em cada um dos quatro cenários econômicos projetados no presente estudo. As barras abaixo do eixo das abcissas indicam fluxos de caixa negativo. A partir do período (em anos) em que as barras ficam acima, sabe-se que o capital investido inicialmente ( $R \$$ $850.000,00$ da britadeira móvel) foi recuperado.

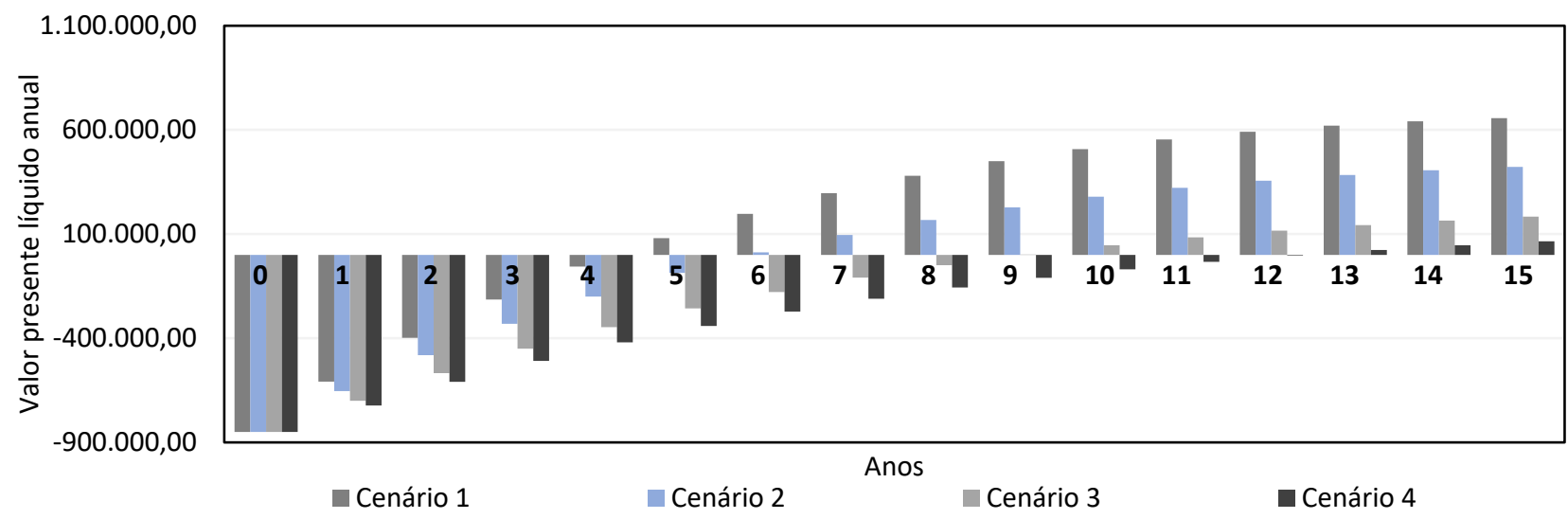

FIGURA 5: Período de recuperação do capital dos cenários econômicos projetados. 
Verifica-se que quanto maior o porte da construtora, mais rapidamente o capital inicial investido é recuperado. No cenário 1 (geração de 1000 toneladas de RCD por mês), o retorno do capital investido acontece já no quinto ano. No cenário 2 (geração de 800 toneladas de RCD por mês), o retorno ocorre no sexto ano. Nos cenários 3 e 4 (geração de 600 e 500 toneladas de RCD por mês, respectivamente) maiores períodos foram necessários para que a recuperação do investimento inicial ocorresse, isto é, 9 e 13 anos, respectivamente.

A maior geração de RCD nos cenários refletem em maiores receitas, uma vez que a quantidade de brita reciclada aumenta e a economia com caçambas de entulho também. Em outras palavras, pode-se dizer que o custo benefício da britadeira é maior para construtoras que geram maiores quantidade de RCD.

Embora todos os cenários tenham apresentado recuperação do capital investido inicialmente, nem todos se mostraram rentaveis financeiramente, em função dos custos necessários à operação e manutanção da britadeira. Os indicadivos de viabilidade econômico-financeira aplicados nos cenários (Tabela 5), mostraram que os projetos dos cenários 3 e 4 resultam em prejuízos severos, um vez que os valores presentes líquidos obtidos foram menores que zero e as taxas internas de retorno foram inferiores à taxa mínima de atratividade (7,9\%). Em síntese, o investidor dos cenários em questão, não deve aplicar seu capital na aquisição de uma britadeira móvel. Talvez, nestes casos em que a geração de RCD é menor, alugar a máquina pode ser uma alternativa para reciclar os RCD gerados.
Por outro lado, os cenários 1 e 2, que produziam mais RCD, mostraram-se financeiramente atrativos. Nestes cenários foram observados valores presentes líquidos superiores a zero e taxas internas de retorno superiores à taxa mínima de atratividade (7,9\%), ou seja, são projetos que acarretariam em riqueza e lucratividade. Ao final dos 15 anos do período do investimento, o cenário 1 resultaria numa riqueza de quase $R \$ 2,9$ milhões e o cenário 2 , numa riqueza de aproximadamente $\mathrm{R} \$ \mathbf{7 1} \mathrm{mil}$.

\section{CONCLUSÕES}

Estima-se que aquisição de uma britadeira móvel visando reciclar os resíduos de concretos e cerâmicos dos RCD's, é um investimento atrativo, desde que os empreendimentos de construção e demolição gerem 800 toneladas por mês de RCD's ou mais. Quanto maior a produção de RCD's, maior será o custo-benefício da aquisição da máquina e, em função da maior quantidade de brita $\mathrm{n}^{\circ} 0$ reciclada (passível de ser utilizada na produção de contrapiso ou comercializada) e da maior economia com caçamba de entulhos, maiores serão as receitas adquiridas, menor será o período de retorno do investimento do capital investido e maior será a rentabilidade financeira dos projetos.

Os benefícios ambientais relacionados à reciclagem de RCD's são inquestionáveis e a utilização de materiais recicláveis como a brita $\mathrm{n}^{\circ} 0$, de acordo com a literatura, não causa perda de qualidade da obra quando bem executada. Neste trabalho, foi verificado que a reciclagem de RCD's também pode ser um negócio economicamente lucrativo.

TABELA 5: Indicativos de viabilidade econômica dos cenários.

\begin{tabular}{lcc} 
& VPL (R\$) & TIR (\%) \\
\hline Cenário 1 & $2.846 .729,77$ & 17,58 \\
Cenário 2 & $70.653,55$ & 8,18 \\
Cenário 3 & $-2.766 .976,46$ & abaixo da TMA \\
Cenário 4 & $-3.320 .403,02$ & abaixo da TMA \\
\hline
\end{tabular}




\section{REFERÊNCIAS BIBLIOGRÁFICAS}

ABRECON, ASSOCIAÇÃO BRASILEIRA PARA RECICLAGEM DE RESÍDUOS DA CONSTRUÇÃO CIVIL E DEMOLIÇÃO. A reciclagem de resíduos de construção e demolição no Brasil. São Paulo, 2015.

ANGULO, S. C. Caracterização de agregados de resíduos de construção e demolição reciclados e a influência de suas características no comportamento de concretos. Tese de doutorado da Escola Politécnica da Universidade de São Paulo. São Paulo, 2005.

ASSOCIAÇÃO BRASILEIRA DAS EMPRESAS DE LIMPEZA PÚBLICA E RESÍDUOS ESPECIAIS (ABRELPE). Panorama dos resíduos sólidos no Brasil em 2016. Publicado em 2017.

BARRA, B. N.; PASCHOARELLI, L. C.; RENÓFIO, A. O ecodesign como ferramenta de auxílio na gestão de resíduos de construção e demolição (RCD). XIII SIMPEP - Bauru, SP, Brasil, 2006.

BARROS, M. M. S. B. de; SABBATINI, F. H. Tecnologia de produção de contrapisos para edifícios habitacionais e comerciais. Boletim Técnico da Escola Politécnica da USP. Departamento de Engenharia de Construção Civil. São Paulo, 1991.

BRASIL. Área de manejo de resíduos da construção e resíduos volumosos: orientação para o seu licenciamento e aplicação da Resolução Conama 307/2002. Ministério das Cidades. Ministério do Meio Ambiente, 2005.

BRASIL. Lei Federal № 12.305, de 2 de agosto de 2010 Institui a Política Nacional de Resíduos Sólidos; altera a Lei no 9.605, de 12 de fevereiro de 1998; e dá outras providências. Brasília, 2010.

Resolução CONAMA no. 307, Gestão dos resíduos da construção civil, Brasília, 2002.

CAMARGO, A. Minas de Entulho. Techne. v. 3, n. 15, p.15-19, 1995.

CASAROTTO, N. F.; KOPITTKE, B. H. Análise de investimentos: matemática financeira, Engenharia econômica, tomada de decisão, estratégia empresarial. 10. ed. São Paulo: Atlas, 2008.

ESPINELLI, U. A gestão do consumo de materiais como instrumento para a redução da geração de resíduos nos canteiros de obras. In: Seminário de gestão e reciclagem de resíduos da construção e demolição - avanços e desafios, 2005, São Paulo. Anais... São Paulo: PCC USP, 2005. 1 CD-ROM.

IPEA, INSTITUTO DE PESQUISAS ECONÔMICAS APLICADAS. Diagnóstico dos Resíduos Sólidos da Construção Civil. Brasília, 2012.
JUNGES, D. M.; KLEINSCHMITT, S. C.; SHIKIDA, P. F. A.; SILVA, J. R. Análise econômico-financeira da implantação do sistema de biodigestores no Município de Toledo (PR). Revista de Economia, v. 35, n. 1, p. 7-30, 2009.

LEVY, SALOMON M. Reciclagem do entulho de construção civil, para utilização como agregado de argamassas e concretos. 1997. Dissertação (mestrado), Escola Politécnica, Universidade de São Paulo, 1997.

MARCONI, M. D. A.; LAKATOS, E. M. Técnicas de pesquisa: planejamento e execução de pesquisas, amostragens e técnicas de pesquisas, elaboração, análise e interpretação de dados. 3.ed. São Paulo: Atlas, 1996.

MILHOMEM, P. M.; SILVA, J. M.; COSTA, P. S. Avaliação das propriedades mecânicas do concreto produzido com resíduo de isoladores elétricos de porcelana. Revista Eletrônica de Engenharia Civil, vol.14, nำ1, 2018.

MIRANDA, L. F. R. A reciclagem de resíduos de construção e demolição no Brasil: 1986-2008. Artigo do Centro de Tecnologia e Geociências. Universidade Federal de Pernambuco. Pernambuco, 2008.

PINTO, T. P. Reciclagem de resíduos da construção urbana no Brasil. Situação atual. In: Reciclagem e reutilização de resíduos como materiais de construção civil. São Paulo, 1996. Anais. Departamento de Engenharia Civil, PCC-USP. São Paulo, 1996. p.159-170.

SPADOTTO, A.; NORA, D. D.; TURELLA, E. C. L.; WERGENES, T. N. DE; BARBISAN, A. O. Impactos ambientais causados pela construção civil. Unoesc \& Ciência - ACSA, Joaçaba, v. 2, n. 2, p. 173-180, 2011.

TONUS, C. A.; MINOZZI, P. I. Utilização de agregados reciclados de alvenaria na produção de concreto para contrapisos. 2013. 67f. Trabalho de Conclusão de Curso (Bacharelado em Engenharia Civil) - Universidade Tecnológica Federal do Paraná. Pato Branco, 2013.

VIEIRA, G. L.; DAL MOLIN, D. C. C. Viabilidade técnica da utilização de concretos com agregados reciclados de resíduos de construção e demolição. Ambiente Construído, Porto Alegre, v. 4, n. 4, p. 47-63, 2004.

ZORDAN, S. E. Entulho da indústria da construção civil. São Paulo, 2000. Disponível em: <http://www.reciclagem. pcc.usp.br/entulho_ind_ccil.htm>. Acesso em 05.jan.2018. 